\title{
AN AUTOMATIC PRINTING SPEED-COUNTER FOR DYNAMO SHAFTING.
}

\author{
BY GEO. S. MOLER.
}

The automatic printing speed-counter was designed and constructed by the writer, to supply a need felt of having a continuous record of the speed of the shafting which drives the dynamos and other apparatus being used by students in their laboratory experiments.

During part of the year the shafting of the dynamo laboratory at Cornell University is driven by water power, the wheels being situated at the bottom of a deep gorge, and several hundred feet distant. The power is transmitted by means of a wire cable running over large grooved sheaves, and the gate hoisting apparatus is operated by a wire rope passing around drums. No automatic regulator has yet been successfully applied to these wheels, so we have to rely upon hand regulation. On account of this, consider. able variations of speed take place, although a tachometer is watched quite closely by the attendant in charge. The variations make it necessary in performing an experiment to continually take account of speed.

The printer (see Fig. 1) is essentially a speed-counter which prints the speed at the end of each minute upon a strip of paper, and does this continuously, requiring very little attention. It was built to give the speed of a shaft which runs at about 140 revolutions per minute, but it has a range of from 30 to 185 per minute.

It is connected to the main shaft of the dynamo laboratory by sprocket-wheels and chains, so that the shaft carrying the worm revolves at exactly the same rate as the main shaft. The 
type-wheel is about eight and one half inches in diameter, and is made by clamping printers type between a disk and a ring fastened with screws to one side of it. The disk has a series of small holes drilled in it at equal distances apart, and dowel pins passing through holes drilled in the type, hold the latter in place. If any of the type become worn, or accidentally bruised, the ring can easily be removed and new ones can be inserted. The type are spaced so as to correspond with the number of teeth of the large gear-wheel which engages with the worm. The printing is done upon a one-half inch tape of district telegraph paper. A typewriter inking ribbon is employed, and as it is fed along, it shifts sidewise back and forth so that the whole width of the ribbon is used. It takes several weeks to go once the length of the ribbon.

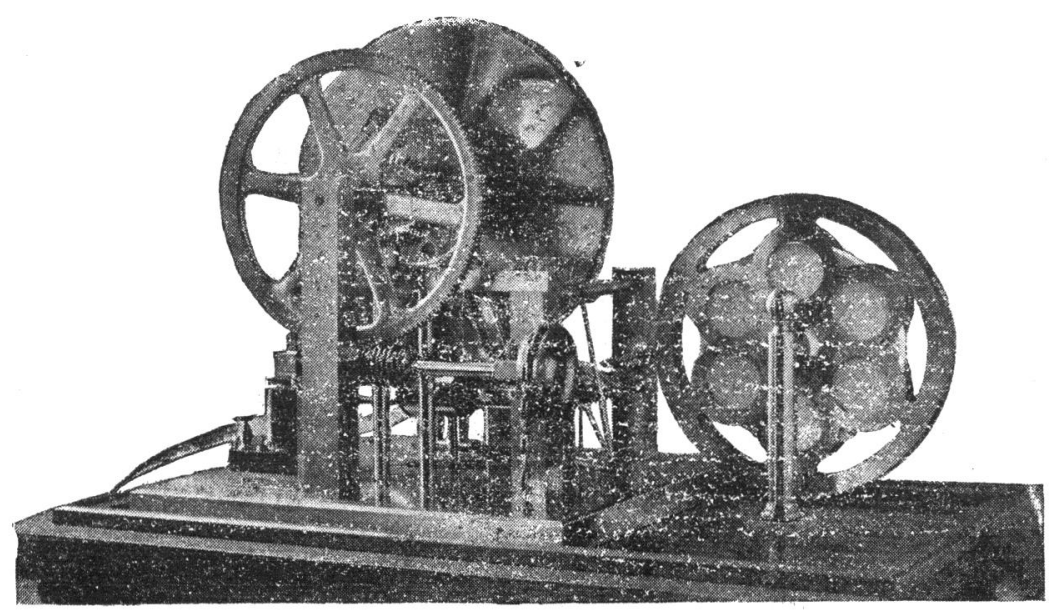

Fici. 1 .

The type wheel practically starts from its zero reading at the beginning of each minute. It is necessary to have it do this, in order that the number printed at the end of the minute shall be the exact number of revolutions for that minute.

When a common speed-counter is used, its index is first set to zero, and it is then applied to the end of the shaft for just one minute, then is withdrawn and read. It is again set to zero, and the operation is repeated, but in doing this, a minute or more is lost each time while setting. Now if the speed were not too great, the index-wheel might be arranged so that it could be 
slipped backward or forward the proper amount, after reading, without stopping the counter. In this way a reading made from zero could be taken each minute. A similar method has been adopted in the printer. The type-wheel, which is held by friction on the shaft, and is carried with it, is at the beginning of the minute slipped backward or forward until it has the correct relative position, then for the remainder of the minute revolves at the same rate as the large gear-wheel on the same shaft. The method of slipping the type-wheel around is partly shown in Figure 2. The toothed wheel $a$, driven by the bevel gear, revolves once for every thirty revolutions of the main shaft. The plate or arm $b$ revolves with it when the pawl $c$ is allowed to catch in the teeth of the wheel. As the plate $b$ goes around with the wheel, the pin $d$ overtakes the arm $e$, which is attached to the type-wheel, and pushes it along slipping the typewheel on the shaft. When $b$ has made one complete revolution, the pin $f$ on the pawl $c$ comes opposite a notch, not shown in the figure, into which it is pushed by a spring, thus pulling the pawl from the wheel, and also holding $b$ stationary. It takes thirty revolutions of the worm to carry the plate $b$ around, it coming to rest just at the end of the thirtieth revolution. If at this instant the priniing hammer were allowed to act, the number 30 would be printed, but if it does not strike till the end of the minute, the type-wheel will move with the large gear-wheel till that time. The striking of the hammer releases the pin $f$, and the pawl which has a spring of its own is again brought in contact with the teeth and so carries the plate $b$ around again. If the type-wheel should complete its revolution before the pin $d$ overtakes the arm $e$, then the arm $e$ comes against another pin which stops it, until the pin $d$ does overtake it. This is the slipping backward which has been mentioned. If the printer should be driven too fast, so that the type-wheel makes a revolution before the minute is up, or if the hammer is not caused to act for several minutes, then it will, the next time it acts, print a zero, which is the type under the hammer while the wheel is held stationary.

The hammer is released at the end of each minute by means of an electro-magnet operated by a clock, and when the hammer makes its stroke, it opens a switch in the electric circuit while the contact in the elock is still closed, so in this manner the spark on breaking the circuit is made at the switch, and not 
at the elock contact. The hammer is set again by a pin on the side of a wheel coming in contact with a lever, and this closes the switch again before the next contact of the clock. When the machinery is not running, the switch remains open, and so the battery materials are not consumed in useless work.

The numbers move past a stationary point which prints its position upon the paper when the hammer makes its blow. If the number printed is exactly opposite the point, then there has been a whole number of revolutions that minute, but, if the number is above or below it, the fraction indicated by its position can easily be determined. Fig. 3, shows how the fraction of a revolution appears on the record. An exact number, 145 is

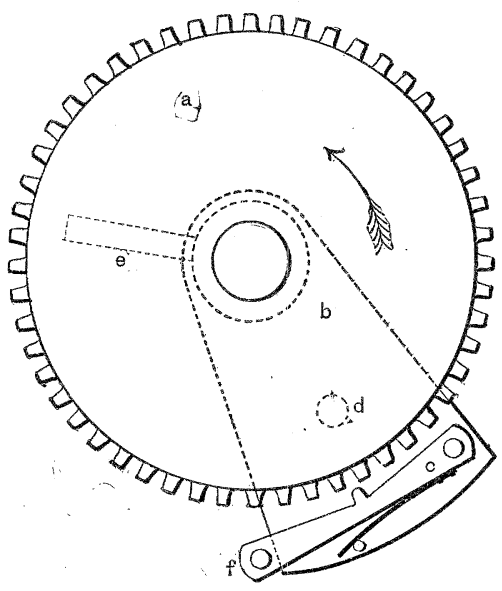

FIG. 2.

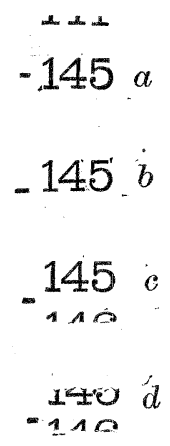

FIG. 3.

shown at $(a), 145.25$ at $(b) 145.5$ at $(c)$ and 145.75 at $(d)$. Usually enough of either the preceding or following number is printed to easily make it out, and to estimate the fraction, which can be read to one fifth of a revolution. In the original design of this instrument the question of adding a time printing device was considered, for it was thought to be necessary to know just the hour and minute that any part of the record was made. Such an attachment was planned but was not built, for the reason that in nearly all cases the record made will be referred to within the first few minutes after it is printed. If it is desirable to mark a certain point on the record to identify it, the paper can be displaced, and so leave a blank at that point. The paper is fed through at the rate of fifteen and one-fourth inches per hour, and so when neces- 
sary this distance can be taken as a unit of length to measure back, and mark off the hours.

One of the ways in which the record obtained is being used, is to find the ratio of its reading to that of the speed of the dynamo being experimented upon, then from the record calculate the speeds for the different parts of the experiment, but this will only answer when the belt is able to drive the machine without slipping.

There is now being built a spindle which is to be tight geared to the main shaft, and which will run ten times faster, or about 1,400 revolutions per minute. This will be for the purpose of testing a student's ability to obtain a correct reading of speed, for the true speed of the spindle will always be ten times the printed speed for that same minute.

The printer which has been described, has been running for about three months and has not failed in any respect to do the work that was expected of it.

The Seroretary:--I have blue prints of a chart prepared by Lieut. Parkhurst, of the Watervliet Arsenal, entitled "Diseases of Dynamos." As there was not time to have it put in type I had blue prints made, which are at the service of members who are interested in the subject.

A recess was then taken until 2 P. $\mathrm{M}$.

Upon reassembling for the afternoon session, Mr. Willyoung presented a paper on "A New Method and Apparatus for Measuring Conductivity."

The following paper by A. H. and C. E. Timmerman on "The Heating of Armatures," was presented by Dr. Nichols. 